\title{
Influences of Cyanobacterial Toxins Microcystins on the Seedling of Plants
}

\author{
Thanh-Son Dao ${ }^{1 *}$, Thai-Hang Le ${ }^{1}$, Thanh-Luu Pham ${ }^{2}$, Lan-Chi Do-Hong ${ }^{3}$, Phuoc-Dan Nguyen ${ }^{4}$ \\ ${ }^{1}$ Institute for Environment and Resources, Ho Chi Minh City, Vietnam; ${ }^{2}$ Graduate School of Life and Environmental Sciences, Uni- \\ versity of Tsukuba, Japan; ${ }^{3}$ Vietnam National University, Ho Chi Minh City, Vietnam; ${ }^{4}$ University of Technology, Ho Chi Minh City, \\ Vietnam. \\ Email: *dao son2000@yahoo.com
}

Received November $26^{\text {th }}$, 2013; revised December 21 $1^{\text {st }}, 2013$; accepted January $9^{\text {th }}, 2014$

Copyright (C) 2014 Thanh-Son Dao et al. This is an open access article distributed under the Creative Commons Attribution License, which permits unrestricted use, distribution, and reproduction in any medium, provided the original work is properly cited. In accordance of the Creative Commons Attribution License all Copyrights @ 2014 are reserved for SCIRP and the owner of the intellectual property Thanh-Son Dao et al. All Copyright (C) 2014 are guarded by law and by SCIRP as a guardian.

\section{ABSTRACT}

Cyanobacterial blooms associated by their toxins have been increasing in frequency in fresh water bodies throughout the world. Among the cyanobacterial toxins, microcystins (MC) are the most common and cause severe adverse impacts on plants, aquatic organisms and human beings. In this study, the effects of MC (at the concentrations of 20 and $200 \mu \mathrm{g} \cdot \mathrm{L}^{-1}$ ) from field water and crude extract of cyanobacterial scum (mainly Microcystis spp.) from the Dau Tieng Reservoir, Vietnam, on the seedlings of three plants, Brassica rapa-chinensis, $B$. narinosa and Nasturtium officinale, were investigated for over a period of 7 days. The results showed that MC reduced the fresh weight, root and shoot length of the exposed seedlings. In addition, abnormalities of leaf shape and color of $B$. rapa-chinensis under exposure to MC were observed. The results implied that MC were taken up and might be accumulated in the seedlings possessing potential risk to consumers as seedlings of these plants are a common food source for Vietnamese. To the best of our knowledge, this is the first report on the effects of MC on B. rapa-chinensis, B. narinosa and $N$. officinale.

\section{KEYWORDS}

Microcystins; Adverse Effects; Fresh Weight; Root and Shoot Length; Abnormalities

\section{Introduction}

In water bodies, microcystins (MC) have been the most commonly reported cyanobacterial toxins compared to other cyanotoxins (e.g. cylindrospermopsin, nodularin, saxitoxins, anatoxin-a(s), anatoxin-a) [1]. Cyanobacterial toxins cause a range of adverse effects on aquatic plants, animals and human beings. In addition, investigations showed that the toxins can accumulate and adversely affect on plants at different aspects of enzymatic responses, photosynthesis, seedlings and growth.

Recently, many studies on bioaccumulation of cyanobacterial toxins (e.g. MC) in plants have been conducted and reported. The uptake and metabolism of MC-LR in stems, rhizomes and leaves of aquatic macrophytes were reported with the MC-LR concentrations being highest in

"Corresponding author. leaves, followed by shoots and lowest in stems [2,3]. Other plants such as broccoli, mustard and duckweed are able to accumulate MC in their leaves and bark protein,

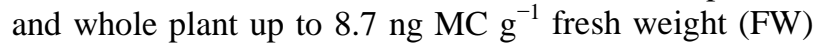
after exposure [4-6]. Furthermore, Microcystis aeruginosa containing MC-LR can also be retained by salad letture (Lactuca sativa) after spraying with irrigation water containing the cyanobacterium [7].

Macrophytes and seedlings have been showed to display the growth inhibition when irrigated with water containing toxic cyanobacterial extract [8]. MC inhibit the growth and development of rape (Brassica napus), rice (Oryza sativa) [9], mustard (Sinapis alba) [4] and Wolffia arrhiza [5]. Exposure to MC-LR resulted in a decrease in germination, roof and leaf length of spinach [10]. MCLR, MC-RR and anatoxin-a also reduced the chlorophyll and carotenoid concentrations in plants $[8,11,12]$ and 
caused malformation on mustard [4].

Pietsch et al. [13] and Wiegand et al. [14] showed that the photosynthesis of macrophytes, Vesicularia dubyana and Ceratophyllum demersum, was inhibited by cyanobacterial crude extracts or purified cyanotoxins, MC, microcin SF608 and anatoxin-a. These authors also recorded the activity alteration of the enzyme glutathione S-transferase in the macrophytes after toxin exposures. The activities of antioxidant and biotransformation enzymes (superoxide dismutase, peroxidase, catalase, glutathione S-transferase, glutathione peroxidase) from plants were also significantly changed by cyanobacterial crude extracts containing MC, pure MC-LR or anatoxina at the concentration from $0.5-10 \mu \mathrm{g} \cdot \mathrm{L}^{-1}[10,12,14]$. MC-LR induced oxidative stress responses in Lepidium sativum seedlings including lipid peroxidation, change of tocopherol concentrations and profile, and elevation of glutathione enzyme activities [15]. MC-RR decreased the glutathione level and increased superoxide dismutase and catalase activities in cells of Arabidopsis thaliana and tobacco (Nicotiana tabucum) $[16,17]$.

Today, seedlings of many different plants are common food ingredients especially in Asia. In the field plants could be irrigated with water containing cyanobacteria and their toxins. Hence these plants could be affected by and accumulate cyanotoxins. To our knowledge, there has been no information on the effects of MC on the seedlings of Brassica rapa-chinensis, B. narinosa and Nasturtium officinale. The aim of this study is to observe the detrimental effects of MC from field water and cyanobacterial crude extract obtained from Dau Tieng Reservoir, Vietnam, at the environmentally relevant concentrations (20 and $200 \mu \mathrm{g} \cdot \mathrm{L}^{-1}$ ) on the seedlings of three different plants B. rapa-chinensis, B. narinosa and $N$. officinale over 7 days.

\section{Materials and Methods}

The seeds of B. rapa-chinensis, B. narinosa and N. officinale were purchased from a super market in Hochiminh City. Two samples: 1) cyanobacterial scum (mainly Microcystis spp) collected in July 2011; and 2) (raw) field water sample during cyanobacterial scum (mainly Anabaena flos-aquae) from Dau Tieng Reservoir collected in September 2012, were used for experiments.

\subsection{Sample Preparation for Experiments and Microcystins Analysis}

Crude extract from cyanobacterial scum collected in July 2011 was prepared according to Pietsch et al. [13] with minor modification. Briefly, the dried biomass of scum on GF/C filters was homogenized, suspended into reversed osmosis water, sonicated, frozen at $-70^{\circ} \mathrm{C}$ over night and thawed at room temperature. The freeze/thaw cycle was repeated five times. After the last thawing cycle, samples were centrifuged at $4500 \mathrm{rpm}, 4^{\circ} \mathrm{C}$ for 15 min. Supernatant was collected and kept at $-70^{\circ} \mathrm{C}$ prior to experiments on the plant seedlings. Field water sample collected in September 2012 was filtered via plankton net (25 $\mu \mathrm{m}$ mesh size) then centrifuged at $4500 \mathrm{rpm}, 4^{\circ} \mathrm{C}$ for $15 \mathrm{~min}$ and supernatant was collected and stored at $-70^{\circ} \mathrm{C}$ prior to exposure to seedlings.

Sub-samples of field water and cyanobacterial crude extract were centrifuged at $14,000 \mathrm{rpm} 4^{\circ} \mathrm{C}$ for $15 \mathrm{~min}$ and supernatants were collected for MC analysis by high performance liquid chromatography (HPLC). HPLC (Shimadzu, Japan) equipped with a silica based reverse phase $\mathrm{C}_{18}$ column (Waters SunFire ${ }^{\mathrm{TM}}$, Ireland) was maintained at $40^{\circ} \mathrm{C}$. A $0.05 \mathrm{M}$ phosphate buffer (pH 2.5) in methanol $(50 / 50, \mathrm{v} / \mathrm{v})$, at a flow rate of $0.58 \mathrm{~mL} \mathrm{~min}^{-1}$, was used as mobile phase. MC congeners were detected by the UV detection at $238 \mathrm{~nm}$ with a photodiode UVvisible array detector. The MC variants MC-RR, -YR and -LR purchased from Wako chemicals company (Osaka, Japan) were used as standards.

\subsection{Exposures of Brassica rapa-chinensis, $B$. narinosa and Nasturtium officinale to Microcystins}

The seedling experiment used 40 seeds of each plant species (with 3 replicates). The seeds were placed on tissues paper and watered daily with $5 \mathrm{~mL}$ of field water (containing 20 (DT20) or 200 (DT200) MC $\mu \mathrm{g} \cdot \mathrm{L}^{-1}$ ) or cyanobacterial crude extract (containing 20 (Sc20) or 200 (Sc200) MC $\mu \mathrm{g} \cdot \mathrm{L}^{-1}$ ). A control was included which consisted of seeds watered with distilled water only. Experiments were run at $25^{\circ} \mathrm{C} \pm 1{ }^{\circ} \mathrm{C}$, in the dark for the first 2 days. From the third day to the end of incubation (7 days), the seedlings were placed under light with an intensity of around 1500 Lux and a light: dark cycle of $12 \mathrm{~h}: 12 \mathrm{~h}$. The parameters recorded were fresh weight (FW), shoot length and root length of the seedlings at 2, 4 and 7 days of incubation. The FW was determined using a balance (Sartorius BP 201S, Germany) and the length was measured with a ruler of $1 \mathrm{~mm}$ spacing.

\subsection{Statistical Analysis}

Sigmaplot, version 12.0 was used for data analysis. Oneway Analysis of Variance (ANOVA) and Tukey test Post $H o c$ were applied to determine the statistically significant differences of the FW, shoot and root length of seedlings after the data were checked for variance homogeneity (Levenes) and normality (Shapiro-Wilk’s test).

\section{Results and Discussion}

\subsection{Microcystins Concentration in the Field Water and Cyanobacterial Crude Extract}

The HPLC analysis showed that the cyanobacterial crude 
extract and field water contained MC-RR, MC-YR and MC-LR (Figure 1) at the total concentrations of 686.9 $\mu \mathrm{g}$ MC-LReq. $\mathrm{g}^{-1}$ dry weight and 1069.2 $\mu \mathrm{g}$ MC-LReq. $\mathrm{L}^{-1}$, respectively (Table 1 ). The MC concentration from cyanobacterial scum sample (collected in July 2011) in this study is in range of previous records from the field in Vietnam [18]. However, the MC concentration in the raw water sample from Dau Tieng Reservoir was much higher than those ever reported before from Vietnamese waters. The high MC concentrations during Microcystis spp and Anabaena flos-aquae scums proposed a serious risk to local residents who daily use the water from the reservoir for domestic activities. Additionally, this is the first report of the MC producing cyanobacterium $A$. flosaquae in Vietnam.
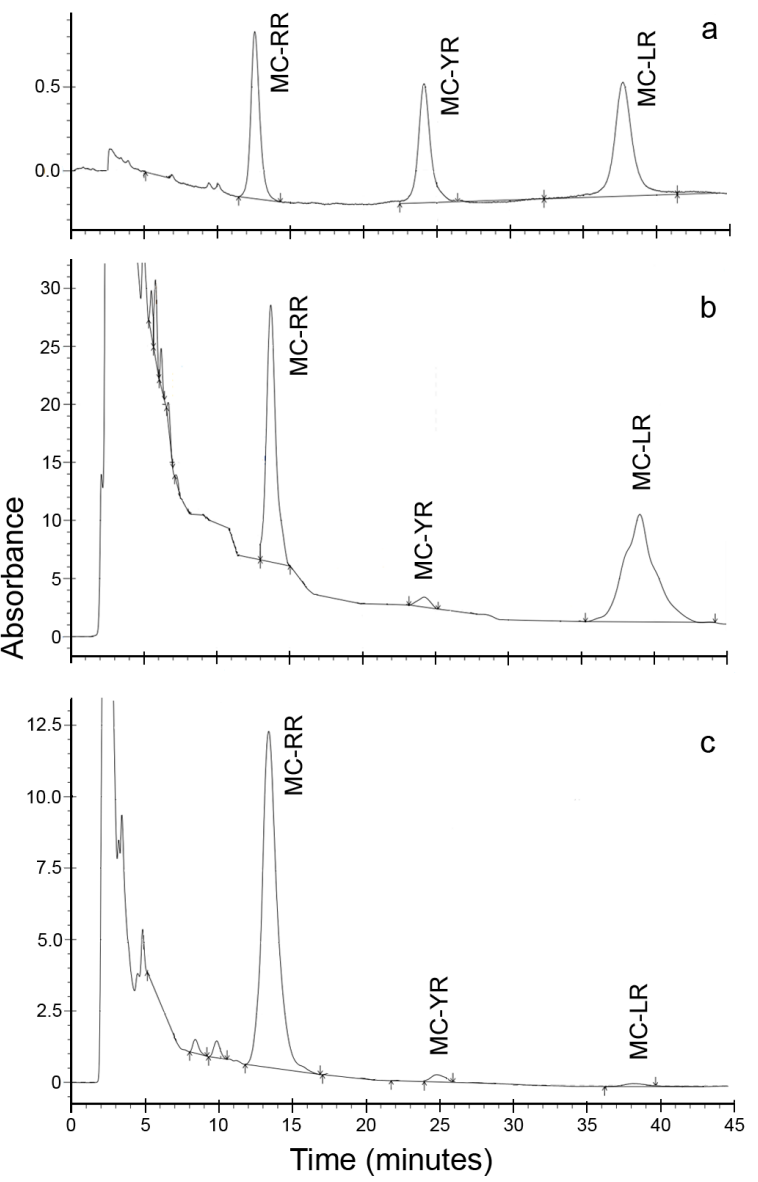

Figure 1. HPLC chromatography of MC from control (a), field water (b) and cyanobacterial scum sample (c).

Table 1. Microcystins concentrations of the cyanobacterial scum ( $\left.\mu g \cdot g^{-1} D W\right)$ and field water sample $\left(\mu g \cdot L^{-1}\right)$.

\begin{tabular}{ccccc}
\hline Samples & MC-RR & MC-YR & MC-LR & Total MC \\
\hline $\begin{array}{c}\text { Cyanobacteria } \\
\text { l scum }\end{array}$ & 635 & 31.7 & 20.3 & 686.9 \\
$\begin{array}{c}\text { Field water } \\
\text { ing.5 }\end{array}$ & 30.6 & 499.1 & 1069.2 \\
\hline
\end{tabular}

\subsection{Effects of Microcystins on the Fresh Weight of Seedlings}

After 2, 4 and 7 days of incubation, the FW of all three plant species from exposures to either field water or cyanobacterial crude extract was significantly decreased compared to the control (ANOVA followed by Tukey test, $\mathrm{p}<0.05$; Figure 2). Besides, high MC concentration (DT200 and Sc200) had a stronger impact than the low toxin one (DT20 and Sc20) on FW of exposed plants consequently lower seedling FW in treatments with 200 $\mu \mathrm{g} \mathrm{MC} \mathrm{L}^{-1}$ compared to that with $20 \mu \mathrm{g} \mathrm{MC} \mathrm{L}^{-1}$. Generally, the FW of seedlings was similar when they were exposed to the same MC concentrations (20 or 200 $\mu \mathrm{g} \cdot \mathrm{L}^{-1}$ ) either from field water or crude extract.

The significantly lower FW of the three seedlings exposed to MC in our study is in line with previous investigations in which the FW of potato and the germination of spinach were inhibited by cyanobacterial crude extract $[8,10]$. The weight of seedlings of the three plants during the first days of germination should be involved in the amount of water they took up. MC induce oxidative stress response [15] and inhibited ATPase [19] possibly interfering the metabolism in seedlings during germination consequently water uptake and seedlings of the exposed seeds and plants. Therefore, from our study it could be inferred that MC reduce the water uptake capacity of seeds hence inhibit FW increase of the seedlings. Besides, the detoxification of MC in plant cells to balance the activities of biotransformation and antioxidant enzymes $[10,12,20]$ would lead to the decrease of the energy or material for growth of the seedlings which properly involved in the reduction of FW of seedlings in the MC exposures compared to the control.

\subsection{Effects of Microcystins on the Development of Root and Shoot}

The root and shoot length of the three plant species in the control treatment always significantly longer than that in MC exposures after 2, 4 and 7 days of incubation (ANOVA followed by Tukey test, $\mathrm{p}<0.05$; Figures 3 and 4). Additionally, high MC concentration from the field water and cyanobacterial crude extract had stronger effects than low MC concentration on the root and shoot development of $B$. rapachinensis, $B$. narmosa and $N$. officmale (Figures 3 and 4). The MC from field water or crude extract at the same concentrations (20 or 200 $\mu \mathrm{g} \cdot \mathrm{L}^{-1}$ ) resulted in the similar root and shoot length of the seedlings.

Inhibition on the root and shoot length of MC-exposed seedlings in our study is consistent with previous records of McElhiney et al. [8] and Pflugmacher et al. [10]. Garbers et al. [21] indicated that MC regulated the phytohormone auxin, and MC were protein phosphatase inhi- 


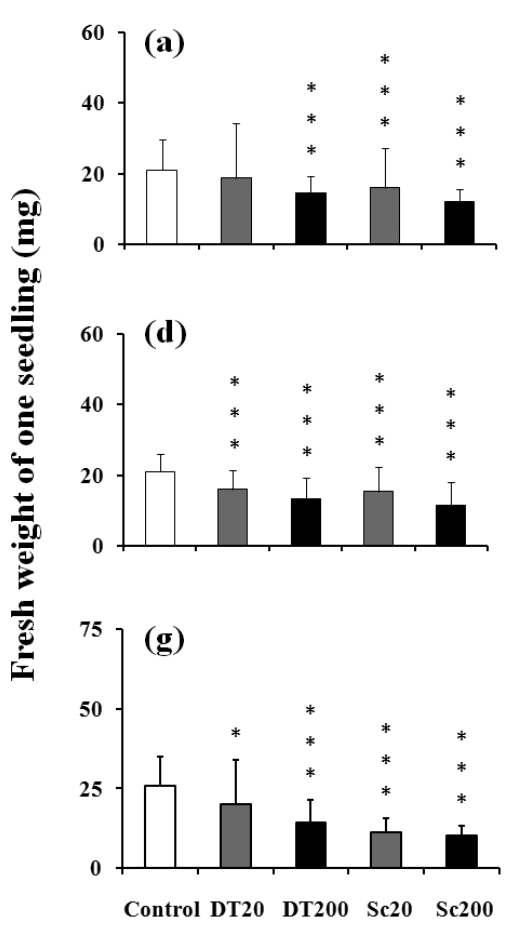

2 days of exposure
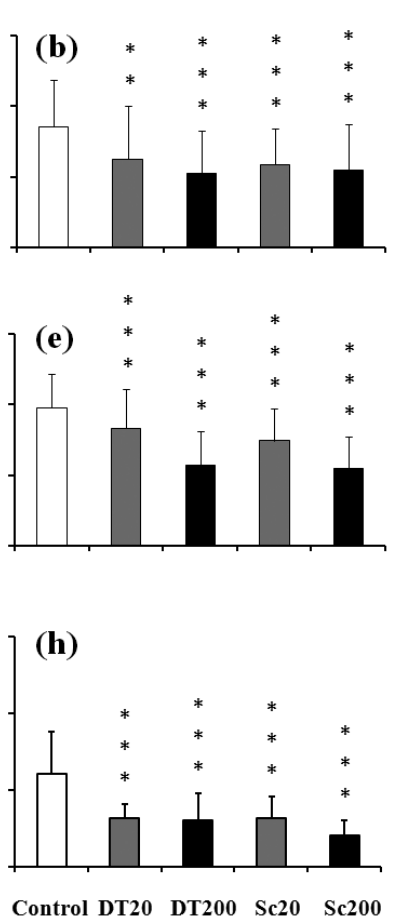

4 days of exposure
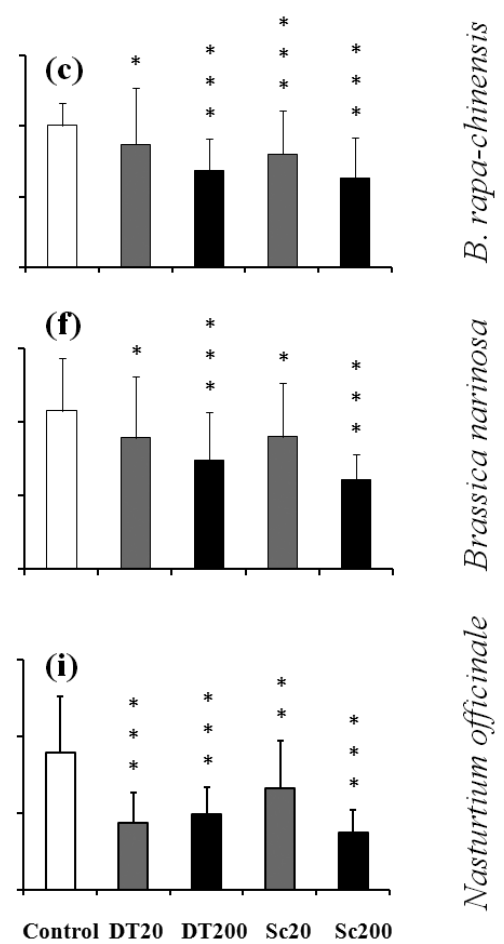

7 days of exposure

Figure 2. Fresh weight $(\mathrm{mg})$ of the seedlings (mean value \pm SD of $\mathbf{n}=40)$ during incubation. Asterisks indicate significant difference between exposures and control by ANOVA followed by Tukey test $(*, p<0.05 ; * *, p<0.01 ; * * *, p<0.001)$.

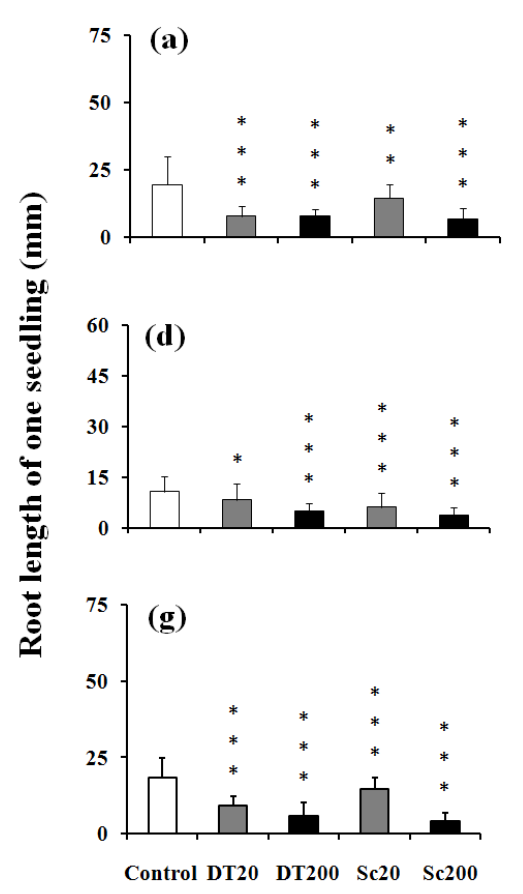

2 days of exposure
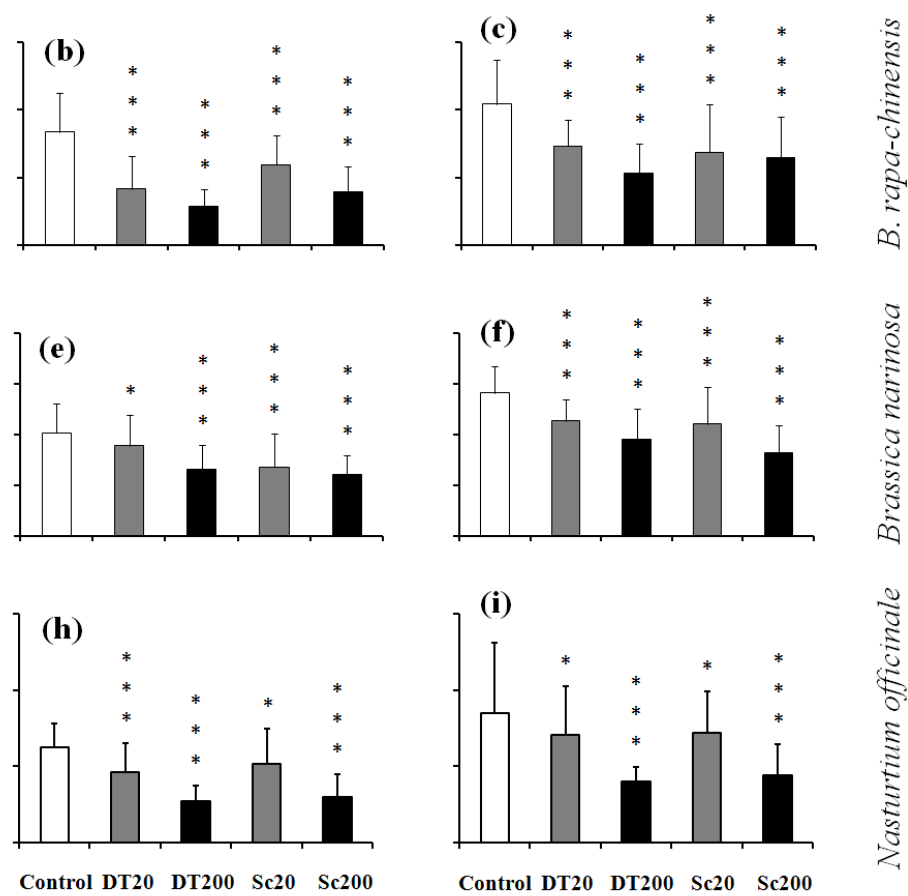

4 days of exposure
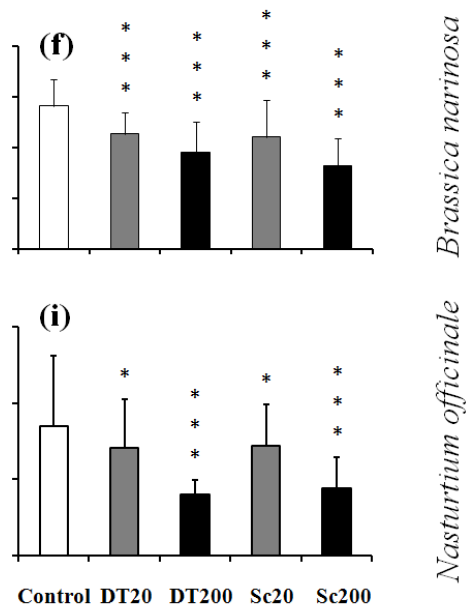

7 days of exposure

Figure 3. Root length $(\mathrm{mm})$ of the seedlings (mean value \pm SD of $\mathbf{n}=40)$ during incubation. Asterisks indicate significant difference between exposures and control by ANOVA followed by Tukey test $\left({ }^{*}, \mathbf{p}<0.05 ; * *, p<0.01 ; * * *, p<0.001\right)$. 


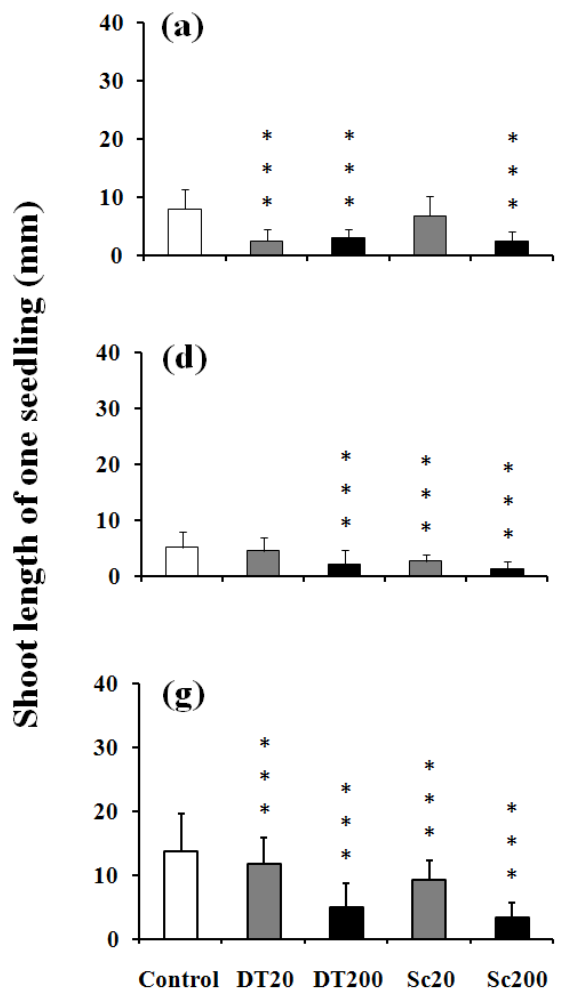

2 days of exposure
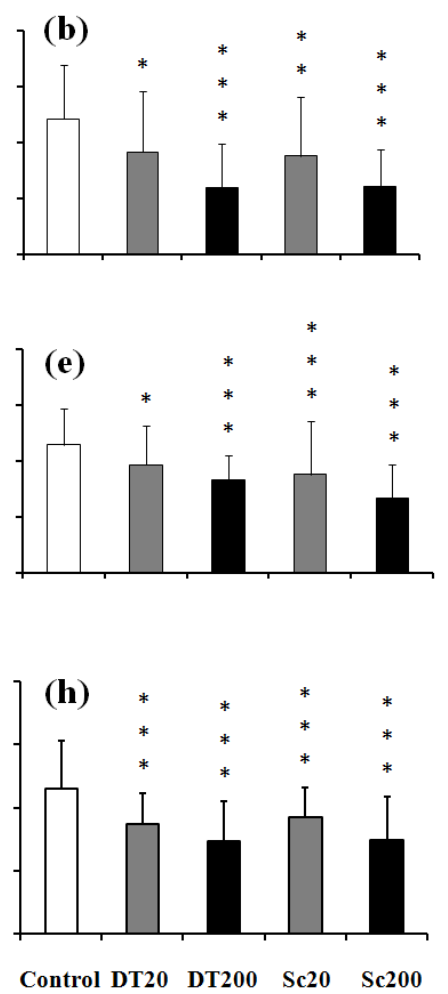

4 days of exposure (c)
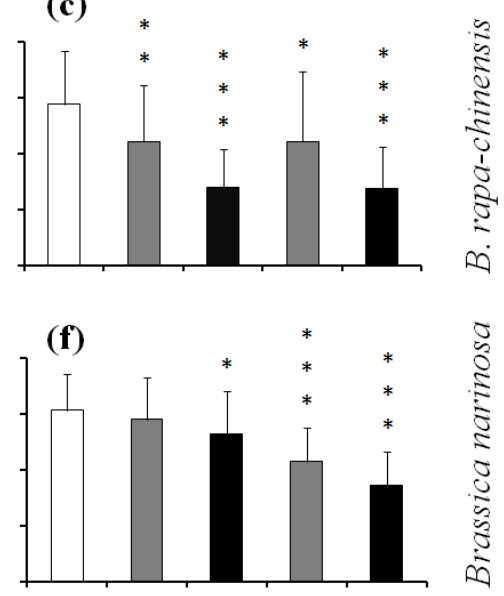

(i)

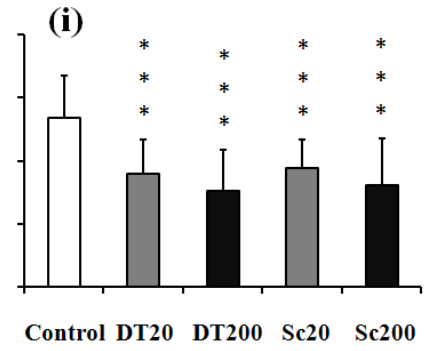

7 days of exposure

Figure 4. Shoot length $(\mathrm{mm})$ of the seedlings (mean value \pm SD of $\mathbf{n}=40)$ during incubation. Asterisks indicate significant difference between exposures and control by ANOVA followed by Tukey test ( $\left.{ }^{*}, \mathbf{p}<0.05 ; * *, \mathbf{p}<0.01 ; * * *, p<0.001\right)$.

bitors. Therefore, exposure to MC would cause the disorder of cell development consequently inhibition of root and shoot growth of the exposed seedlings. Also, the water uptake reduction induced by MC as mentioned above would contribute to the decrease of shoot and root prolongation. Besides, MC could cause strong alteration of biotransformation and antioxidant enzyme activities in plants $[10,12,20]$ hence some energy is spent on the MC detoxification leading to the reduction of hydrocarbon and nutrient source for root and shoot development. Summing up the adverse effects MC on plants, the seedlings exposed to MC would grow slower than those in the control as observed in our experiments.

\subsection{Abnormalities of the Seedlings Exposed to Microcystins}

Among the MC exposures, abnormalities of leaf shape and color of some seedlings of B. rapa-chinensis were observed. The two young leaves on some seedlings from MC exposure were quite difference in size, and the leaf margin of those seedlings were brown (Figure 5(b)) while young leaves were almost similar in size with green color in the control incubation (Figure 5(a)).

Gehringer et al. [22] found that the leaves of Lepidium sativum exposed to MC were significantly shorter than control samples which supported the unbalanced size of two young leaves observed in our study. It is possible that the brown color on leaf margin of $B$. rapa-chinensis in this investigation has been involved in the disappearance or decrease of chlorophyll content at the margin which was previously reported elsewhere [4]. This phenomenon could also be explained as chlorophyll is inhibited by $\mathrm{MC}$ at the concentrations from $5-50 \mu \mathrm{g} \mathrm{L}{ }^{-1}[8]$ which were in the range with or below the MC concentrations in our study $\left(20-200 \mu \mathrm{g} \cdot \mathrm{L}^{-1}\right)$.

\section{Conclusion}

Microcystins concentration in water from Dau Tieng Reservoir was extremely high possessing high risk to local residents who daily use the water from the reservoir for their domestic activities. MC from the field water sample and crude extract of cyanobacteria caused adverse effects on seedling of the tested plants including significant decreases in FW, root and shoot length. These effects could be involved in the alteration of regulated (protein phosphatase), energetic (ATPase), biotransformation (glutathione S-transferase) and antioxidant (catalase) enzyme activities caused by MC. Besides, abnormalities of leaf shape and brown color from B. rapachinensis seedlings exposed to MC after one week could 


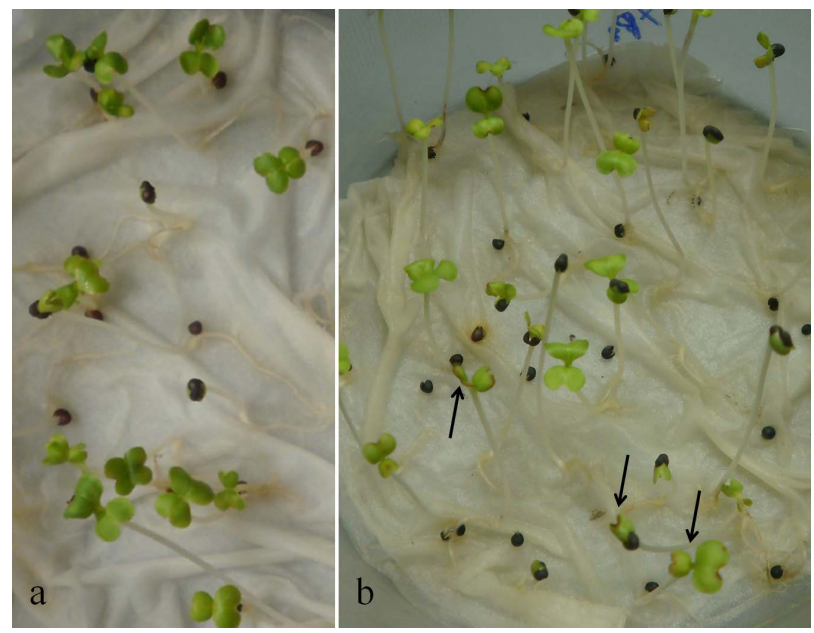

Figure 5. Normal leaves from control (a) and abnormal leaves from MC exposure (b) of Brassica rapa-chinensis at 7 days of incubation. Arrows indicate the difference in size and the brown color at margin of the young leaves.

be attributed to the impact of MC on chlorophyll content. The results of this study confirm the potent toxicity of cyanobacterial toxins from Dau Tieng Reservoir on plants. To our knowledge, this is the first report on the effects of MC on seedlings of B. rapa-chinensis, B. narinosa and $N$. officinale.

\section{Acknowledgements}

This study is funded by the Vietnam National UniversityHochiminh City under the granted projects numbers B2012-24-01TD and A2013-48-01.

\section{REFERENCES}

[1] K. Sivonen and G. Jones, “Cyanobacterial Toxins,” In: I. Chorus andJ. Bartram, Eds., Toxic Cyanobacteria in Water-A Guide to Their Public Health Consequences, Monitoring and Management, E \& FN Spon, London, 1999, pp. 41-111.

[2] S. Pflugmacher, C. Wiegand, K. A. Beattie, G. A. Codd and C. E. W. Steinberg, "Uptake of the Cyanobacterial hepatotoxin Microcystin-LR by Aquatic Macrophytes," Journal of Applied Botany, Vol. 72, No. 5-6, 1998, pp. 228-232.

[3] S. Pflugmacher, C. Wiegand, K. A. Beattie, E. Krause, C. E. W. Steinberg and G. A. Codd, "Uptake, Effects and Metabolism of Cyanobacterial Toxins in the Emergent Reed Plant Phragmites australis (Cav.) Trin. ex Steud," Environmental Toxicology and Chemistry, Vol. 20, No. 4, 2001, pp. 846-852.

[4] K. Kurki-Helasmo and J. Meriluoto, "Microcystin Uptake Inhibits Growth and Protein Phosphatase Activity in Mustard (Sinapis alba L.) Seedlings,” Toxicon, Vol. 36, No. 12, 1998, pp. 1921-1926. http://dx.doi.org/10.1016/S0041-0101(98)00114-7

[5] S. M. Mitrovic, O. Allis, A. Furey and K. J. James, "Bio- accumulation and Harmful Effects of Microcystin-LR in the Aquatic Plants Lemna minor and Wolffia arrhiza and the Filamentous Alga Chladophora fracta,” Exotoxicology and Environmental Safety, Vol. 61, No. 3, 2005, pp. 345-352. http://dx.doi.org/10.1016/j.ecoenv.2004.11.003

[6] S. Jarvenpaa, C. Lundberg-Niinisto, L. Spoof, O. Sjovall, E. Tyystjarvi and J. Meriluoto, "Effects of Microcystins on Broccoli and Mustard, and Analysis of Accumulated Toxin by Liquid Chromatography-Mass Spectrometry," Toxicon, Vol. 49, No. 6, 2007, pp. 865-874. http://dx.doi.org/10.1016/j.toxicon.2006.12.008

[7] G. A. Codd, J. S. Metcalf and K. A. Beattie, "Retention of Microcystis aeruginosa and Microcystin by Salad Lettuce (Lactuca sativa) after Spray Irrigation with Water Containing Cyanobacteria,” Toxicon, Vol. 37, No. 8, 1999, pp. 1181-1185.

[8] J. McElhiney, LA. Lawton and C. Leifert, "Investigations into the Inhibitory Effects of Microcystins on Plant Growth, and the Toxicity of Plant Tissues Following Exposure,” Toxicon, Vol. 39, No. 9, 2001, pp. 1411-1420. http://dx.doi.org/10.1016/S0041-0101(01)00100-3

[9] J. Chen, L. Song, J. Dai and Z. Liu, "Effects of Microcystins on the Growth and the Activity of Superoxide Dismutase and Peroxidase of Rape (Brassica napus L. ) and Rice (Oryza sativa L.),” Toxicon, Vol. 43, No. 4, 2004, pp. 393-400. http://dx.doi.org/10.1016/j.toxicon.2004.01.011

[10] S. Pflugmacher, M. Aulhorn and M. Grimm, "Influence of a Cyanobacterial Crude Extract Containing Microcystin-LR on the Physiology and Antioxidative Defence Systems of Different Spinach Variants,” New Phycologist, Vol. 175, No. 3, 2007, pp. 482-489. http://dx.doi.org/10.1016/j.toxicon.2004.01.011

[11] J. Weiss, H. P. Liebert and W. Braune, "Influence on Microcystin-RR on Growth and Photosynthetic Capacity of the Duckweed Lemma minor L.," Journal of Applied Botany, Vol. 74, No. 3-4, 2000, pp. 10-105.

[12] M. H. Ha and S. Pflugmacher, "Phytotoxic Effects of the Cyanobacterial Neurotoxin Anatoxin-a: Morphological, Physiological and Biochemical Responses in Aquatic Macrophyte, Ceratophyllum demersum," Toxicon, Vol. 70, 2013, pp. 1-8. http://dx.doi.org/10.1016/j.toxicon.2013.03.021

[13] C. Pietsch, C. Wiegand, M. V. Ame, A. Nicklisch, D. Wunderlin and S. Pflugmacher, "The Effects of Cyanobacterial Crude Extract on Different Aquatic Organisms: Evidence for Cyanobacterial Toxin Modulating Factors," Environmental Toxicology, Vol. 16, No. 6, 2001, pp. 535542. http://dx.doi.org/10.1002/tox.10014

[14] C. Wiegand, A. Peuthert, S. Pflugmacher and S. Carmeli, "Effects of Microcin SF608 and Microcystin-LR, Two Cyanobacterial Compounds Produced by Microcystis sp., on Aquatic Organisms,” Environmental Toxicology, Vol. 17, No. 4, 2002, pp. 400-406. http://dx.doi.org/10.1002/tox.10065

[15] J. Stuven and S. Pflugmacher, "Antioxidative Stress Response of Lepidium sativum Due to Exposure to Cyanobacterial Secondary Metabolites,” Toxicon, Vol. 50, No. 1, 2007, pp. 85-93. 
http://dx.doi.org/10.1016/j.toxicon.2007.02.019

[16] L. Yin, J. Huang, W. Huang, D. Li and Y. Liu, "Responses of Antioxidant System in Arabidopsis thaliana Suspension Cells to the Toxicity of Microcystin-RR," Toxicon, Vol. 46, No. 8, 2005, pp. 859-864. http://dx.doi.org/10.1016/j.toxicon.2004.12.025

[17] L. Yin, J. Huang, W. Huang, D. Li, G. Wang and Y. Liu, "Microcystin-RR-Induced Accumulation of Reactive Oxygen Species and Alteration of Antioxidant Systems in Tobaco BY-2 Cells,” Toxicon, Vol. 46, No. 5, 2005, pp. 507-512. http://dx.doi.org/10.1016/j.toxicon.2005.06.015

[18] T. S. Dao, T. L. Pham, L. C. Do-Hong and B. T. Bui, "Occurrence of Toxic Cyanobacteria and Their Toxins from Freshwater Bodies in Vietnam-A Short Review," Vietnam Journal of Science and Technology, Vol. 50, No. 1C, 2012, pp. 264-269.

[19] A. Mikhailov, A. S. Harmala-Brasken, J. Herman, J. A. O. Meriluoto and J. E. Eriksson, "Identification of ATP-
Synthetase as a Novel Intracellular Target for Microcystin-LR,” Chemico-Biological Interactions, Vol. 142, No. 3, 2003, pp. 223-237. http://dx.doi.org/10.1016/S0009-2797(02)00075-3

[20] S. Pflugmacher, "Promotion of Oxidative Stress in the Aquatic Macrophyte Ceratophyllum demersum during Biotransformation of the Cyanobacterial Toxin Microcystin-LR," Aquatic Toxicology, Vol. 70, No. 3, 2004, pp. 169-178. http://dx.doi.org/10.1016/j.aquatox.2004.06.010

[21] C. Garbers, A. DeLong, J. Deruere, P. Bernasconi and D. Soll, "A Mutation in Protein Phosphatase 2A Regulatory Subumit A Affects Auxin Transport in Arabidopsis," The EMBO Journal, Vol. 15, No. 9, 1996, pp. 2115-2124.

[22] M. M. Gehringer, V. Kewada, N. Coates and T. G. Downing, "The Use of Lepidiium sativum in a Plant Bioassay System for the Detection of Microcystin-LR,” Toxicon, Vol. 41, No. 7, 2003, pp. 871-876. http://dx.doi.org/10.1016/S0041-0101(03)00049-7 